\title{
Uso de Preservativo en Brasil: Una Mirada a la Producción Académica sobre la Prevención de VIH/SIDA (2007-2011)
}

\author{
Thiago Félix Pinheiro ${ }^{1^{*}}$ \\ Escuela de Medicina de la Universidad de São Paulo, São Paulo, Brasil \\ Gabriela Junqueira Calazans \\ Centro de Referencia y Capacitación en VIH / SIDA del Departamento de Salud \\ del Estado de São Paulo, São Paulo, Brasil \\ José Ricardo de Carvalho Mesquita Ayres \\ Departamento de Medicina Preventiva de la Universidad de São Paulo, São Paulo, Brasil
}

\section{Resumen}

Desde el comienzo de la epidemia del sida, el preservativo ha sido la principal estrategia de prevención de las políticas brasileñas. Este estudio presenta un ensayo reflexivo sobre la producción académica respecto al uso del preservativo como método de prevención del VIH/sida en Brasil, basado en artículos publicados en revistas científicas entre los años 2007 y 2011 e indexados en la Biblioteca Virtual en Salud. Se traza un panorama de los estudios realizados, de los resultados y conclusiones encontrados. A pesar de la diversidad en la producción analizada, se identifica una concentración de estudios realizados con jóvenes y una gran atención dada a los problemas de género. A partir de un análisis conjunto de los objetivos y del aporte teórico-metodológico de los artículos, se identificaron seis vertientes de producción del conocimiento sobre el tema: estudios epidemiológicos, estudios de conocimientos y comportamientos, estudios de contextos específicos, estudios de significados y sentidos, estudios de actividades y estudios de revisión. La literatura analizada se presenta de forma difusa, de manera que se entrelazan enfoques y orientaciones, lo que requiere una madurez epistemológica y metodológica de las referencias utilizadas.

Palabrasclave:Preservativo/condón,prevencióndelsida, sexoseguro,infeccionesdetransmisiónsexual.

\section{Uso de Camisinha no Brasil: Um Olhar sobre a Produção Acadêmi- ca Acerca da Prevenção de HIVIAids (2007-2011)}

\section{Resumo}

Desde o início da epidemia de aids, a camisinha tem sido a principal estratégia de prevenção das políticas brasileiras. Este estudo apresenta um ensaio reflexivo sobre a produção acadêmica a respeito do uso da camisinha como método de prevenção de HIV/aids no Brasil, com base em artigos publicados em periódicos científicos entre 2007 e 2011 e indexados na Biblioteca Virtual de Saúde. Delineia-se um panorama dos estudos realizados e dos resultados e conclusões encontrados. A despeito da diversidade da produção analisada, identifica-se concentração de estudos realizados com jovens e grande atenção dada às questões de gênero. A partir de uma análise conjunta dos objetivos e do aporte teórico-metodológico dos artigos, são identificadas seis vertentes de produção de conhecimento sobre o assunto: estudos epi-

Dirección de envío: Departamento de Medicina Preventiva, Faculdade de Medicina, Universidade de São Paulo, Av. Doutor Arnaldo, 455, $2^{\circ}$ andar, sala 2213, Cerqueira César, São Paulo, SP, Brasil, 01246-903. E-mail: tfpinheiro@usp.br, gajuca@usp.bre jrcayres@usp.br

Agencia financiera: Fundação de Amparo à Pesquisa do Estado de São Paulo (FAPESP). 
demiológicos; estudos de conhecimentos e comportamentos; estudos de contextos específicos; estudos de significados e sentidos; estudos de atividades; e estudos de revisão. A literatura analisada apresenta-se de forma difusa, de modo a entrelaçar abordagens e direcionamentos, o que demanda um amadurecimento epistemológico e metodológico dos referenciais utilizados.

Palavras-chave: Preservativo/camisinha, prevenção de aids, sexo seguro, infecções sexualmente transmissíveis.

\title{
Condom Use in Brazil: An Overview of the Academic Production on HIVIAIDS Prevention (2007-2011)
}

\begin{abstract}
Since the beginning of the AIDS epidemic, condoms have been the main preventive strategy of the Brazilian policies. This study presents a reflective essay on the academic production on condom use as a method for HIV/AIDS prevention in Brazil, based on papers published in scientific journals between 2007 and 2011 and indexed in the Virtual Health Library. It outlines an overview of these studies and their results and conclusions. Despite the diversity of the production analyzed, it was found that the studies concentrated on young people, with great attention given to gender issues. From combined analysis on the goals and the theoretical and methodological frameworks of the articles, six areas of production of knowledge on the subject were identified: epidemiological studies; studies on knowledge and behavior; studies on specific contexts; studies on senses and meanings; studies on activities; and review studies. The literature analyzed is presented in a diffuse manner so as it interlocks approaches and directions, which requires an epistemological and methodological maturity of the frameworks used.
\end{abstract}

Keywords: Condom, AIDS prevention, safe sex, sexually transmitted infections.

\section{Prevención del VIH/sida y Uso del Preservativo}

La epidemia del sida, por el carácter incurable de la enfermedad, se presentó como un importante desafío para la Salud Pública. En dicho escenario, la reducción de daños y la prevención se destacaron como estrategias fundamentales para el enfrentamiento de la epidemia. En Brasil, desde el inicio de las políticas públicas relacionadas al sida, el preservativo fue, y continúa siendo, la principal arma en el campo de la prevención (Paiva, Venturini, França, \& Lopes, 2003). La promoción del uso del preservativo formó parte de una perspectiva no supresora de la prevención, que caracteriza la mayoría de respuestas nacionales de gran suceso contra la epidemia del VIH, contrariamente de otros contextos, donde los trabajos preventivos persistieron sobre la idea de la abstinencia sexual (Kalichman, 1993).
La propuesta original de adoptar el uso del preservativo como estrategia de prevención del $\mathrm{VIH} /$ sida, viene desde la primera década de la epidemia, en 1980, con la iniciativa del movimiento gay organizado en los Estados Unidos. Este grupo se negó a aceptar las propuestas provenientes de la Salud Pública, que preconizaban el "aislamiento sanitario" de los grupos poblacionales en los que, de acuerdo con los estudios epidemiológicos de esa época, la oportunidad de encontrar personas con la enfermedad era mayor que en la población general, los llamados grupos de riesgo. Fue con la resistencia a ese concepto y a las estrategias de abstinencia y aislamiento, que se propuso la centralidad del concepto de comportamiento de riesgo y, sobre esta base, la incorporación del preservativo como forma de prevención que posibilite el mantenimiento de las prácticas sexuales (Ayres, Calazans, Saletti, \& França, 2006). 
De esta manera, la promoción del uso del preservativo se articula, en una historiografía de los conceptos operativos de la prevención del sida, a la superación de la idea de grupos de riesgo por una concepción comportamental de la prevención, articulada en términos de comportamientos de riesgo versus prácticas seguras. Ese proceso produjo una tendencia a la universalización de la preocupación por el sida, siendo posible trabajar más abiertamente y con mayor legitimidad las informaciones y orientaciones relacionadas con las prácticas de sexo (más o menos) seguras y difundir y enseñar cómo usar el preservativo. Se plasmó en la prevención, la lógica del marketing, que enfatiza la propaganda del preservativo asociado a las prácticas y comportamientos que también se desean vender (Paiva, 2000).

Luego, y en un intento por responder a la percepción de que el riesgo de exposición de las personas al VIH y al sida no deriva sólo de un conjunto de aspectos individuales, fue elaborada la perspectiva de la vulnerabilidad, que propone analizar los aspectos individuales, así como los colectivos y del contexto, que conllevan a una mayor susceptibilidad a la infección y a la enfermedad e, inseparablemente, a la mayor o menor disponibilidad de recursos de todo orden para protegerse de ambos (Ayres et al., 2006). De acuerdo con Paiva (2000), la perspectiva de la vulnerabilidad tornó evidentes las limitaciones de las campañas de difusión del preservativo, hechas de forma descontextualizada, no suficientemente explícita o específica para cada grupo con sus propios valores, preferencias sexuales particulares y lenguajes diferentes para tratar de la sexualidad.

La adopción del concepto de vulnerabilidad como guía de las políticas de prevención y de cuidado en el contexto nacional se articula a la "incorporación de la perspectiva de género y a la garantía de los derechos humanos ... [como] condiciones fundamentales para la reducción de las vulnerabilidades y para la prevención de las infecciones de transmisión sexual y el VIH/sida" (Ministério da Saúde [MS], 2009). En el Brasil, la idea de sexo protegido por el uso del preservativo se integra, como vemos, a la perspectiva de los derechos humanos, siendo identificada en el uso del preservativo, una posibilidad de ligar el trabajo preventivo con un concepto positivo de los derechos sexuales, que más allá de garantizar la protección (contra violaciones y enfermedades), promueve el derecho al placer, a la vida sexual satisfactoria y segura (Petchesky, 1999).

Con la disponibilidad gratuita y universal de la terapia antirretroviral en el Brasil desde mediados de la década de 1990 y el consiguiente aumento de la población que vive con el VIH, surgió la cuestión del cuidado a las personas en dichas condiciones, principalmente, en el ámbito de la salud sexual. En ese contexto, el sexo protegido se fortaleció como una posibilidad de garantizar la continuidad de la vida sexual de esas personas y la protección contra la (re)infección.

Por otro lado, desde finales de la década de 1990 y a lo largo de la década de 2000, han sido frecuentes las quejas y observaciones sobre lo que convencionalmente se llamaba la "fatiga del preservativo" o "fatiga de la prevención", como se puede observar en publicaciones de medios internacionales ${ }^{2}$, y en el ámbito de introducciones y justificaciones de algunos artículos científicos que se basaron en este fenómeno social para investigar la prevención del sida (Adam, Husbands, Murray, \& Maxwell, 2005; Ostrow et al., 2008).

No es casual, en este sentido, que estemos entrando en la cuarta década de la lucha contra la epidemia presenciando una fuerte inversión en todo el mundo, en las formas de prevención biomédica del VIH, tales como los microbicidas, la profilaxis pre-exposición (PrEP, del inglés pre-exposure prophylaxis), la profilaxis post-exposición (PEP, del inglés post-exposure

\footnotetext{
Sobre "fatiga del preservativo" o "fatiga de la prevención", revisar: (a) "Condom fatigue" may be behind STI rise: University of British Columbia. Recuperado el 10 de junio de 2012, de http://www.ctv.ca/CTVNews/Health/20070913/ bc_sex_070913/; (b) "Condom Fatigue" Leading To More AIDS. Recuperado el 10 de junio de 2012, de http://www.goldtalk.com/forum/ showthread.php?t=23956; (c) Condom Fatigue or Prevention Fatigue? Recuperado el 10 de junio de 2012, de http://ezinearticles.com/?CondomFatigue-Or-Prevention-Fatigue?\&id=5196308.
} 
prophylaxis), estrategia de probar y tratar, el tratamiento como prevención y las vacunas. Sin embargo, incluso pareciendo estrategias prometedoras, éstas han sido vistas por muchos programas, como herramientas que deben integrarse a la estrategia de promoción del uso del preservativo en las políticas de prevención del VIH/sida de gran alcance poblacional. Se cree que sólo así será posible hacer de esta cuarta década, la última de la epidemia del sida (Joint United Nations Programme on HIV/AIDS [UNAIDS], 2012; Organización de la Naciones Unidas, 2011).

Tomando como perspectiva la centralidad del preservativo en la lucha contra la epidemia del sida, la actualidad del debate y la diversidad de la producción académica al respecto, presentamos, en este artículo, un ensayo reflexivo sobre la producción académica acerca del uso del preservativo como estrategia de prevención del $\mathrm{VIH} /$ sida en Brasil. El análisis se realiza sobre la base de estudios publicados en revistas científicas en los últimos cinco años. Asumimos que la reflexión sobre estos estudios, sus referenciales teóricos y sus diseños metodológicos, puede contribuir a la comprensión de los desafíos actuales en el campo de la prevención y a la dirección de nuevos estudios comprometidos con la transformación de los contextos de vulnerabilidad al VIH enfrentados en el país.

\section{Camino Metodológico}

El levantamiento de la producción académica acerca del tema investigado fue realizada a través de búsqueda bibliográfica en marzo de 2012, en la Biblioteca Virtual en Salud (BVS) ${ }^{3}$. Este portal reúne las bases de datos más importantes del área de la salud (LILACS, MEDLINE, COCHRANE, SciELO), configurándose una opción amplia y práctica para la investigación de artículos disponibles por medio del acceso online y abierto al público.

Seleccionamos los trabajos que presentaron, en su título, los descriptores en portugués " $c a$ misinha", preservativo, sexo seguro, prevenção de aids. La investigación también se realizó con

3 http://brasil.bvs.br los mismos descriptores en inglés (condom, safe sex, AIDS prevention), agregando el término Brazil. De los trabajos encontrados, se mantuvieron sólo aquellos artículos disponibles como texto completo, publicados durante los últimos cinco años (de 2007 a 2011). Se excluyeron los estudios realizados en otros países, los que no trataban del uso del preservativo como método de prevención del VIH/sida o de Infecciones de Transmisión Sexual (ITS) de forma general y aquellos cuya dirección online estaba inactiva, sin poder tener acceso por el link brindado por la BVS ni por otras plataformas de búsqueda (por ejemplo, Google). Finalmente, un total de 38 artículos fueron seleccionados para componer el material de análisis.

Fue necesario el recorte temporal, dada la gran cantidad de artículos encontrados en las primeras búsquedas. Representando todavía, una limitación de este estudio, ya que abarca apenas la producción más reciente sobre la temática.

Los artículos seleccionados recibieron un primer análisis con el fin de tener una visión panorámica de la producción académica sobre la adopción del preservativo como estrategia de prevención del VIH/sida, a partir de características como la fuente y el año de publicación, los participantes y la región donde se realizó la investigación. Seguidamente, realizamos un análisis más detallado, a partir de los objetivos, el aporte teórico-metodológico y los resultados de los estudios. El proceso analítico consistió en lectura exploratoria, selectiva y analítica de los artículos.

\section{Panorama de la Literatura: Contextos de la Producción y Difusión del Conocimiento}

Los artículos analizados (Tabla 1) fueron publicados durante los cinco años investigados, siguiendo una distribución no lineal, de modo que no podemos inferir un aumento o disminución de las publicaciones acerca del uso del preservativo como estrategia de prevención del VIH/ sida durante este intervalo de tiempo. Identificamos pocos estudios de ámbito nacional, siendo la gran mayoría realizados en lugares específicos del Brasil. Existen estudios en todas las regiones 
Tabla 1

\section{Caracterización de los Artículos Revisados}

\begin{tabular}{|c|c|c|c|c|c|}
\hline $\begin{array}{l}\text { Año de } \\
\text { publica- } \\
\text { ción }\end{array}$ & $\mathrm{N}^{\circ *}$ & Autores & Participantes del estudio** & $\begin{array}{l}\text { Local } \\
\text { del estudio }\end{array}$ & $\begin{array}{l}\text { Área de conocimiento } \\
\text { de la revista } \\
\text { científica**** }\end{array}$ \\
\hline \multirow[t]{5}{*}{2007} & 1 & Leite et al. & Universitarios/as & PI & Enfermería \\
\hline & 2 & Carvalho, Bezerra, Leitão, Joca y Pinheiro & Jóvenes $* * *$ & $\mathrm{CE}$ & Enfermería \\
\hline & 3 & Maliska, Souza y Silva & Mujeres con VIH & $\mathrm{SC}$ & Enfermería \\
\hline & 4 & $\begin{array}{l}\text { Benzaken, Galbán Garcia, Sardinha, } \\
\text { Pedrosa y Paiva }\end{array}$ & - & $\mathrm{AM}$ & Salud Pública \\
\hline & 5 & Viana, Faúndes, Mello y Sousa & Estudiantes*** & MG & Salud Pública \\
\hline \multirow[t]{11}{*}{2008} & 6 & S. M. Barbosa, Costa y Vieira & Padres de adolescentes $* * *$ & $\mathrm{CE}$ & Enfermería \\
\hline & 7 & Alves y Lopes & Universitarios/as & SP & Enfermería \\
\hline & 8 & Marta, Francisco, Martins y Clos & Universitarios/as & $\mathrm{RJ}$ & Enfermería \\
\hline & 9 & Madureira y Trentini (a) & Parejas heterosexuales & - & Enfermería \\
\hline & 10 & Saldanha et al. & Estudiantes*** & PB & IST \\
\hline & 11 & Lima, Silva, Godoi y Merchán-Hamann & $\begin{array}{l}\text { Hombres que hacen sexo con } \\
\text { hombres }\end{array}$ & $\mathrm{DF}$ & Medicina \\
\hline & 12 & $\begin{array}{l}\text { Berquó, Barbosa, Lima y Grupo de Estudos } \\
\text { em População, Sexualidade e Aids }\end{array}$ & Pob. urbana en general & Brasil & Salud Pública \\
\hline & 13 & $\begin{array}{l}\text { Paiva, Calazans, Venturi, Dias y Grupo de } \\
\text { Estudos em População, Sexualidade e Aids }\end{array}$ & Adolescentes $* * *$ & Brasil & Salud Pública \\
\hline & 14 & Oliveira, Moura, Guedes y Almeida & Profesionales de salud (ITS/Sida) & $\mathrm{CE}$ & Salud Pública \\
\hline & 15 & M. C. P. Sousa, Espírito Santo y Motta & Mujeres & PI & Salud Pública \\
\hline & 16 & Madureira y Trentini (b) & Hombres heterosexuales & $\mathrm{SC}$ & Salud Pública \\
\hline \multirow[t]{9}{*}{2009} & 17 & R. K. Reis y Gir & Parejas serodiscordantes & SP & Enfermería \\
\hline & 18 & Kalckmann, Farias y Carvalheiro & Mujeres & SP & Epidemiología \\
\hline & 19 & Matos, Veiga y Reis & Estudiantes*** & MG & Ginec./Obstetricia \\
\hline & 20 & Moura, Lima, Farias, Feitoza y Barroso & Prostitutas & $\mathrm{CE}$ & ITS \\
\hline & 21 & Brisighelli, Araújo, Doher y Haddad & - & - & Medicina \\
\hline & 22 & Costa, Rosa y Battisti & Universitarios/as & $\mathrm{SC}$ & Salud Pública \\
\hline & 23 & Ferraz y Nemes & - & SP & Salud Pública \\
\hline & 24 & Maksud & Parejas serodiscordantes & - & Salud Pública \\
\hline & 25 & $\begin{array}{l}\text { A. A. Sousa, Lucareski, Brizolara, } \\
\text { Bortoletto y Pinto }\end{array}$ & - & SP & Salud Pública \\
\hline \multirow[t]{4}{*}{2010} & 26 & Nicolau y Pinheiro & Prisioneras & $\mathrm{CE}$ & Enfermería \\
\hline & 27 & Sampaio, Paixão, Andrade y Torres & Adolescentes $* * *$ & PE e BA & Psicología \\
\hline & 28 & Riscado, Oliveira y Brito & Mujeres quilombolas & $\mathrm{AL}$ & Salud Pública \\
\hline & 29 & Cruzeiro et al. & Adolescentes $* * *$ & RS & Salud Pública \\
\hline \multirow[t]{9}{*}{2011} & 30 & Maschio, Balbino, Souza y Kalinke & Ancianos/as & PR & Enfermería \\
\hline & 31 & Laroque et al. & Ancianos /as & $\mathrm{RS}$ & Enfermería \\
\hline & 32 & Gomes, Fonseca, Jundi y Severo & Parejas heterosexuales & $\mathrm{RS}$ & Enfermería \\
\hline & 33 & Ribeiro, Silva y Saldanha & Jóvenes*** & $\mathrm{PB}$ & ITS \\
\hline & 34 & Albuquerque y Villela & Mujeres & $\mathrm{CE}$ & $\begin{array}{l}\text { Administración } \\
\text { de Cuidados }\end{array}$ \\
\hline & 35 & Rebello, Gomes y Souza & Hombres & - & Salud Pública \\
\hline & 36 & Sampaio, Santos, Callou y Souza & Adolescentes $* * *$ & PE e BA & Salud Pública \\
\hline & 37 & C. B. Reis y Bernardes & Presidiarios/as & MS & Salud Pública \\
\hline & 38 & Borba & Travestis que se prostituyen & Sur del Brasil & Salud Pública \\
\hline
\end{tabular}

Nota. *Número de identificación del artículo, utilizado para organización de nuestro análisis. **De acuerdo con la denominación presente en los artículos. ***Participantes de ambos sexos. ****De acuerdo con la clasificación de la BVS. 
del país, con menor expresión de estudios desarrollados en el Centro-Oeste y en el Norte.

De acuerdo con la clasificación de las revistas científicas presentes en la BVS, los artículos analizados se concentran en revistas vinculadas a la Salud Pública y a la Enfermería, lo que muestra un estrechamiento de la discusión en este sentido, en dichas áreas. Seguidamente, y con menor proporción, encontramos artículos publicados en revistas relacionadas con Medicina y otras áreas de la Salud, destacándose el área de las ITS. Se resalta la presencia de un único artículo publicado en una revista de Psicología.

La mayoría de artículos se detienen en el estudio del preservativo masculino, sin embargo, algunos incluyen o estudian exclusivamente el preservativo femenino. En este punto, no manejamos una separación basada en ese criterio, ya que consideramos el uso del preservativo de forma general. En algunos artículos, el preservativo como método de prevención del VIH/sida es el tema central. En otros, ese tema se encuentra insertado en el tema más amplio de la prevención de ITS. Existen todavía, artículos en que la temática se articula a otras discusiones, como la iniciación sexual, la anticoncepción, la violencia, el racismo, el uso de servicios de salud, etc.

En la literatura analizada, se encuentran los términos "camisinha", preservativo y condom, utilizados en la búsqueda de las bases de datos bibliográficos. En la presente descripción en español; sin embargo, utilizamos de manera uniforme el término preservativo, aún cuando el texto original hace uso de otras expresiones. En la versión en portugués, utilizamos el término "camisinha", que en contexto brasileño nos parece estar más asociado a enfoques que valoran los aspectos socio-culturales de las prácticas sexuales y a perspectivas de prevención, orientadas por el marco de la vulnerabilidad y de los derechos humanos; a diferencia de términos con tendencia a discursos en una línea más estrictamente biomédica de la infección, centrados en las estrategias preventivas de protección específica ${ }^{4}$.

Para la comparación entre fundamentos y métodos de los principales cuadros conceptuales de prevención, revisar: Ayres, Paiva y França (2011).

\section{Conocimiento Producido: Sistematización de los Estudios y Presentación de los Resultados}

Los artículos presentan una diversidad significativa relacionada con lo que se proponen investigar y el diseño de las investigaciones; por lo tanto, son diversos, al respecto del tipo de conocimiento producido. De esa forma, para apreciación y discusión de los estudios encontrados y de sus resultados, nos pareció útil agruparlos a partir de un análisis conjunto de los objetivos y del aporte teórico-metodológico. Identificando así, seis vertientes de estudios acerca de la adopción del preservativo como estrategia de prevención del VIH/sida (Tabla 2).

Dicha sistematización tiene el propósito de discutir qué tipo de conocimiento se ha producido en el campo en cuestión y en qué se basa; sin embargo, no abarca todos los elementos que caracterizan los estudios y que podría dar lugar a otras formas de análisis de los mismos.

A partir de estas vertientes, que representan lógicas diferentes en la construcción del conocimiento en el campo investigado, pasamos a presentar los estudios y sus resultados.

\section{Estudios Epidemiológicos}

Entre los estudios centrados en la prevalencia del uso del preservativo, destacamos los de nivel nacional. En esa dirección, dos artículos analizados presentan datos de la investigación sobre Comportamiento Sexual y Percepciones de la Población Brasileña sobre el VIH/sida, recolectados en 1998 y 2005, como muestras representativas de la población urbana del país.

Berquó et al. (2008) presentan datos sobre el uso del preservativo por personas de 16 a 65 años de edad, en los 12 meses anteriores a la investigación e indican un aumento substancial de 1998 para 2005. Ese aumento se verifica entre las personas que tienen solamente parejas eventuales (de $63,5 \%$ para $78,6 \%$ ), las que tienen sólo pareja estable (de $19,1 \%$ para $33,1 \%$ ) y las que tienen ambos tipos de parejas (de 24,5\% para 46,3\%). Como vemos, la prevalencia del uso del preservativo en el primer grupo es superior a la prevalencia en los otros grupos. De manera general, en 
Tabla 2

Caracterización de las Vertientes de Estudios sobre el Uso del Preservativo como Estrategia de Prevención del VIH/Sida

\begin{tabular}{ll}
\hline Vertiente $\quad$ Caracterización & $\begin{array}{l}\text { Artículos identificados } \\
\text { por categoría }\end{array}$ \\
\hline
\end{tabular}

Estudios Identifican la prevalencia del uso del preservativo o de alguna epidemiológicos

Estudios de conocimientos y comportamientos

Estudios de contextos específicos

Estudios de significados y sentidos

Estudios de actividades

Estudios d e revisión ocurrencia relacionada en determinado grupo/segmento poblacional y/o investigan factores asociados con la adopción de esta práctica. Adoptan metodología cuantitativa.

Buscan identificar el nivel de informaciones que determinado grupo detiene al respecto de las ITS/Sida y de los métodos preventivos, así como el relato de prácticas sexuales y comportamientos relacionados al uso del preservativo. Se fundamentan en el enfoque comportamental de la prevención del VIH/sida (comportamientos de riesgo $V s$. prácticas seguras). Hay una variación y combinación de metodologías cuantitativa y cualitativa.

Se circunscriben a un contexto determinado de investigación, en la búsqueda por comprender las posibilidades y los desafíos en la prevención del VIH/sida en situaciones o con grupos específicos. Priorizan el estudio de los aspectos socioculturales. Adoptan metodología cualitativa.

Atienden a significados y sentidos atribuidos por personas o grupos al uso del preservativo o al sexo desprotegido, buscando comprender como las construcciones simbólicas al respecto de esas prácticas pueden dificultar o posibilitar la prevención. Adoptan metodología cualitativa.

Presentan estudios de casos de actividades que promueven el uso del preservativo como medida de prevención del VIH/Sida o estudios que envuelven tales actividades como parte de la investigación y analizan las posibilidades y desafíos de la situación estudiada. Se justifican por la difusión de experiencias que pueden ser tomadas como ejemplos o que merecen debate. Engloban también las investigaciones participativas. Adoptan predominantemente metodología cualitativa.

Realizan revisión de estudios producidos sobre el uso del preservativo como estrategia de prevención del VIH/sida y los resumen y/o analizan bajo determinado referencial teórico o recorte temático. Pueden alcanzar una diversidad de estilos y caminos en el trabajo de revisión de la literatura.
$5,11,12,13,18,22,29$, 30,33

$1,2,6,7,8,10,14,19$, 26,31

$15,20,28,37$

$3,9,16,17,24,27,32$ 36

\section{$4,23,25,34,38$}

21,35 el año 2005, 21\% de las personas afirman haber usado constantemente el preservativo, o sea, en todas las relaciones sexuales en los 12 meses investigados. Los jóvenes (de 16 a 24 años) se destacan como el grupo que más se protege.

Paiva et al. (2008) se detienen específicamente en los participantes jóvenes de esa investigación (de 16 a 19 años) e investigan específicamente el uso del preservativo en la iniciación sexual. Siguiendo la dirección de los resultados del estudio anterior, identifican un aumento tanto en el caso en que la primera experiencia ocurrió en una relación estable (de 48,5\% para $67,7 \%$ ), como en el caso de una pareja eventual (de $47,2 \%$ para $62,6 \%$ ). Este aumento no se produce para algunos jóvenes, basado en la religión (protestantes y sin religión), el ingreso familiar y el haber tenido la primera relación sexual antes de $\operatorname{los} 14$ años.

Los demás artículos de esta vertiente presentan investigaciones llevadas a cabo con ciertos segmentos poblacionales y en locales específicos del país. La mayoría se centra en investigaciones del uso del preservativo entre jó- 
venes, como el estudio de Cruzeiro et al. (2010), que presenta una investigación desarrollada en el domicilio con una muestra representativa del grupo etario de 15 a 18 años, residentes de la zona urbana de la ciudad de Pelotas/RS. En este estudio, se investiga la ocurrencia de "comportamientos sexuales de riesgo", definidos en razón de la cantidad de parejas sexuales en los últimos 12 meses y del uso del preservativo en las tres últimas relaciones. Con respecto a esta segunda indicación, el uso del preservativo fue constante para $56,3 \%$ de los participantes. Para las chicas, el riesgo de usar el preservativo sólo ocasionalmente aumenta en $21 \%$, en comparación con los chicos. Los autores observan una tendencia lineal con relación a la escolaridad materna, ya que el uso ocasional muestra tanto mayor como menor los años de estudio de la madre.

Costa et al. (2009), Ribeiro et al. (2011) y Viana et al. (2007) también investigan el uso del preservativo en la población joven, pero en esos casos, únicamente con jóvenes insertados en el sistema educativo. Los dos primeros comparan el uso del preservativo en la primera relación sexual y en la más reciente.

Costa et al. (2009) identifican entre universitarios con edad promedio de 23,6 años, la prevalencia de $71,4 \%$ en la primera relación sexual y de $61,4 \%$ en la última. En cuanto a los factores asociados, esta investigación muestra que tener candidiasis es un factor de protección para el uso del preservativo en la primera y en la última relación sexual. Además, la relación matrimonial no estable y tener una pareja del curso del área de la salud se asocian positivamente al uso de preservativos en la última relación sexual. Por otro lado, pertenecer a un curso del área de la salud no se asoció significativamente al uso del preservativo.

Ribeiro et al. (2011), a su vez, observan, que entre los estudiantes de escuela pública (de 12 a 20 años), la ausencia del preservativo disminuyó para el sexo masculino (de $35 \%$, en la primera relación, para $21 \%$ en la última) y aumentó para el sexo femenino (de $39 \%$ para $43 \%$ ). Tomando como referencia todas las relaciones sexuales, la diferencia por sexo también es significativa en este estudio. La mayoría de los chicos (53\%) afirma usar preservativo siempre, mientras la mayoría de las chicas (54\%) afirma usarlo algunas veces. Para los investigadores, esa diferencia puede deberse al hecho de que la mayoría de las relaciones estables $(68 \%)$ es manifestada por las mujeres mientras que los hombres (38\%) afirman haber tenido cuatro o más relaciones sexuales. Sin embargo, los demás datos relacionados al tipo y a la cantidad de relaciones no son presentados en el artículo.

Otros factores asociados al uso del preservativo entre jóvenes son encontrados por Viana et al. (2007). Estos investigadores identifican entre estudiantes sexualmente activos de escuelas públicas con edades entre 10 y 19 años, que ser del sexo masculino y tener profesionales de salud en la educación, están asociados positivamente con todos los indicadores de sexo seguro investigados, así como tener madre con más de ocho años de escolaridad está positivamente asociado con el uso del preservativo con la pareja estable o casual; ser alumno de nivel secundario (en comparación con ser alumno de nivel primario) y ser de mayor edad, se asocian negativamente con el uso consistente del preservativo con la pareja casual y estable, respectivamente.

El uso del preservativo también es investigado entre otros grupos en los estudios de esta vertiente. La población senil, por ejemplo, es foco de investigación de Maschio et al. (2011), quienes investigan las medidas de prevención de ITS/sida adoptadas por usuarios de una institución que desarrolla programas para mejorar la calidad de vida en la tercera edad. En ese estudio, la mayoría de los participantes $(87,7 \%)$ manifiesta la necesidad de utilizar medidas de prevención, entre las cuales el uso del preservativo se destaca como la medida más conocida (señalada por $70 \%$ de los participantes). Sin embargo, sólo $42,8 \%$ afirma haber adoptado alguna medida preventiva, entre los cuales, $64,2 \%$ se refieren al uso del preservativo.

El estudio de Kalckmann et al. (2009) se ocupa específicamente del uso del preservativo femenino. En el monitoreo del uso de ese preservativo en los servicios públicos de salud (que participaron de un proyecto de implantación de dicho insumo), los investigadores identifican la continuidad del uso por un período de 12 me- 
ses en sólo 14,4\% de las mujeres investigadas. Las mujeres con mayor frecuencia de relaciones sexuales por mes, usan ese preservativo por un período de tiempo más prolongado, así como aquellas que utilizan los servicios de salud de proyectos comunitarios (en comparación con las que utilizan las unidades básicas y servicios especializados). El hecho de adoptar alguna práctica anticonceptiva y el método escogido no están asociados a la continuidad de su uso.

El estudio de Lima et al. (2008) trata sobre los hombres que tienen sexo con hombres (HSH) e investiga, entre otros aspectos relacionados con el uso de los servicios de salud (dirigidos a las ITS), la adquisición del preservativo. Al respecto, los investigadores identifican que, entre los participantes, los hombres más jóvenes compran los preservativos con una frecuencia significativa, pero menor en relación a los hombres de mayor edad. En relación a la clase económica, los hombres de menor poder adquisitivo demuestran tener menor acceso al preservativo, principalmente, en "locales de encuentros gay". De acuerdo con la tabla que presenta las formas de acceso al preservativo, es posible identificar, en general, que la compra de preservativos o su adquisición en "locales de encuentros gay" y eventos es más significativa que su adquisición en servicios de salud y organizaciones no gubernamentales.

\section{Estudios de Conocimientos y Comportamientos}

Los estudios de conocimientos y comportamientos suelen valerse de modelos teórico-metodológicos basados en enfoques comportamentales y socio-cognitivos, tales como el Estudio de Conocimientos, Actitudes y Prácticas (Alves \& Lopes, 2008; Marta et al., 2008; Nicolau \& Pinheiro, 2010); la Teoría de Etapas de Cambio (S. M. Barbosa et al., 2008); la Teoría del Comportamiento Planificado (Matos et al., 2009); y The Behavioral Risk Factor Surveillance System (Saldanha et al., 2008).

También, en esta vertiente, la mayoría de artículos se destina a la investigación del uso del preservativo entre jóvenes. Sin embargo, cada estudio presenta sus peculiaridades en función del segmento investigado y del diseño de la investigación.

Los estudios de Alves y Lopes (2008) y de Marta et al. (2008) proponen análisis que alcanzan Conocimientos, Actitudes y Prácticas de jóvenes. Alves y Lopes (2008), en su investigación con jóvenes universitarios entre 18 y 19 años, sobre la píldora anticonceptiva y el preservativo, identifican que los participantes poseen conocimiento elevado y actitudes positivas relacionados al tema, pero, en el relato de las prácticas, se verifica procedimientos inadecuados, como la colocación del preservativo apenas en el momento de la penetración, cuando, según las autoras, "lo más adecuado sería su uso durante toda la relación sexual, antes de cualquier contacto genital" (p. 15). A pesar que el estudio enfoca la anticoncepción, aborda también la prevención de ITS/sida al tratar del uso del preservativo. Al respecto, prácticamente todos los participantes afirmaron la necesidad del uso del preservativo en todas las relaciones sexuales; un número significativo $(65,1 \%)$ no tendría relaciones sexuales si su pareja no quisiese utilizar el preservativo, mas, un grupo de ellos $(17,6 \%)$ tendría relaciones sin protección si conociese bien a la pareja. Además, 46,1\% de los universitarios consideraban que el preservativo no interfiere en las relaciones sexuales y $23,1 \%$ afirman que genera disminución del placer sexual.

Por otro lado, la investigación de Marta et al. (2008) se propone delinear el perfil de los estudiantes del curso de pregrado en Enfermería frente al sida. En ese estudio, la mayoría de los participantes presenta informaciones correctas sobre las formas de transmisión del VIH. El preservativo se destaca como el método preventivo más informado (91,7\%). Entre los participantes sexualmente activos, 58,8\% afirman haber usado el preservativo en la primera relación sexual. Sin embargo, esa medida no es aplicada por $48,5 \%$ después de un mes de relación, cuando ésta pasa a ser considerada estable y sin riesgos.

Otros estudios se detienen, más específicamente, en los comportamientos relacionados al uso del preservativo como estrategia de prevención de ITS/sida. Entre ellos, el artículo de Saldanha et al. (2008) describe el comportamiento sexual y "perfiles de vulnerabilidad" al sida en- 
tre estudiantes de 13 a 18 años. Para las investigadoras, la iniciación sexual precoz con la pareja de mayor edad y las múltiples parejas configuran factores que aumentan la vulnerabilidad y se agravan por el uso no consistente del preservativo. En ese sentido, el 54\% parece afirmar que usan el preservativo siempre ${ }^{5}$. El estudio investiga el conocimiento de los jóvenes apenas relacionado a los métodos anticonceptivos, lo que es manifestado por el $56 \%$ de los participantes, siendo el preservativo el más citado (64\%).

En esa dirección, Carvalho et al. (2007) realizan una investigación con jóvenes de 18 a 50 $a^{n}{ }^{6}{ }^{6}$, que frecuentan discotecas. En ese contexto, las investigadoras, además de indagar sobre la práctica del sexo protegido, verificaron si los participantes portaban y cómo mantenían el preservativo. De acuerdo con los resultados, 58,8\% de los entrevistados afirmaron usar siempre el preservativo y $38,4 \%$ lo portaban en el momento de la investigación, siendo que $40,7 \%$ de los que tenían un preservativo, lo portaban en la billetera. Se observó la relación entre la acomodación y las condiciones del embalaje, todos los preservativos que estaban aplastados se encontraban en las billeteras. Entre los motivos para la no adopción del uso del preservativo se destacan el uso de anticonceptivo hormonal $(43,2 \%)$ y la queja de que el preservativo disminuye el placer $(29,6 \%)$.

Matos et al. (2009) también se refieren al comportamiento, con foco en los factores que motivan la práctica de sexo seguro entre jóvenes estudiantes de 18 a 19 años. Siguiendo esa línea, buscan identificar los antecedentes de la intención del uso del preservativo entre los participantes y concluyen que la formación de

5 En el artículo de Saldanha et al. (2008), hay un desencuentro entre algunas informaciones referentes a la frecuencia del uso del preservativo, presentadas en la tabla y en el resumen.

6 Aunque sea poco común la denominación "jóvenes" a un grupo con este recorte de edad, las investigadoras, al parecer, utilizaron este término basado en el hecho de más de la mitad de los participantes tener entre 18 y 23 años, siendo el promedio de las edades igual a 22,56, la moda, 18 años y la mediana, 21 años. la intención no depende tanto de las actitudes, pero sí de normas sociales y de percepciones de control comportamental, o sea, de la creencia personal al respecto del grado de facilidad en realizar el comportamiento. En este sentido, la obligación moral de usar el preservativo es mayormente expresada por los hombres que por las mujeres. Sin embargo, ellas se muestran menos susceptibles a la tentación de hacer sexo sin preservativo y manifiestan menor dificultad en impedir que el sexo suceda en esa condición. En relación a la presión social, médicos y madres de familia se destacan como las influencias más expresivas sobre la intención de usar el preservativo, especialmente, entre las mujeres.

Leite et al. (2007), a su vez, enfatizan sobre el proceso de elección del método anticonceptivo y de prevención de ITS/sida entre universitarios del área de la salud. Identificaron, entre estos, una elección casi unánime por el preservativo como método anticonceptivo. Entre los chicos, la elección se justifica, principalmente, por la practicidad y bajo costo; entre las chicas, por la ausencia de efectos colaterales. De modo general; sin embargo, tal elección no está vinculada a la prevención de ITS/sida, lo que llama la atención de las autoras por tratarse de la perspectiva de futuros profesionales de salud.

Los profesionales de salud, también son investigados por Oliveira et al. (2008), que indagan, entre médicos y enfermeros de instituciones públicas de referencia para el tratamiento de ITS, el conocimiento sobre el preservativo femenino y la dinámica de promoción de ese método. Los resultados apuntan hacia un déficit del conocimiento relacionado a las características básicas y al modo de colocación entre los profesionales de las dos categorías. Sin embargo, conocer los pasos para la colocación se muestra asociado al sexo femenino. Además, se corrobora la poca promoción del uso del preservativo femenino, justificada por los profesionales, basado en el precio elevado, en la no disponibilidad en las unidades de salud, en el desconocimiento y en la falta de adherencia de las mujeres, frente a un mayor acceso al preservativo masculino.

El estudio de S. M. Barbosa et al. (2008) abordó padres de adolescentes, estudiantes de 
escuelas públicas. Las investigadoras estudiaron las Etapas de Cambios del Comportamiento con respecto a la comunicación con los hijos sobre sexualidad y las medidas preventivas del VIH/ sida. Los resultados indicaron que la mayoría de los padres conversan o tienen interés en conversar con sus hijos sobre esa temática. Pero, algunos expresan dificultades para hacerlo, principalmente, la necesidad de una mayor explicación sobre las medidas preventivas del VIH/sida o el embarazo no deseado.

El comportamiento de las personas de la tercera edad en relación a la prevención de las ITS/ sida es estudiado por Laroque et al. (2011), ellos identificaron diversos factores que contribuyen a la poca adherencia de ese grupo poblacional al uso del preservativo, principalmente, en el período post-reproductivo. Entre ellos, está la vergüenza para hablar sobre la sexualidad y el proponer el uso del preservativo, la resistencia y el prejuicio sobre el preservativo, dado que ese grupo poblacional inició su vida sexual antes de la epidemia del sida; y el hecho de que la práctica sexual en esa etapa de la vida ya implica algunas limitaciones, las cuales se suman a la introducción del preservativo. Además, según las autoras, la prevención dirigida a esa población se choca con la dificultad que tienen los profesionales de la salud al abordar la sexualidad de las personas de la tercera edad.

Finalmente, en los textos analizados, encontramos un prólogo de Nicolau y Pinheiro (2010), que difunde una investigación a ser realizada con prisioneras sobre Conocimientos, Actitudes y Prácticas relacionados a los preservativos masculino y femenino.

\section{Estudios de Contextos Específicos}

Entre los estudios de esta vertiente, que se caracterizan por el abordaje de contextos específicos valiéndose de los aspectos socioculturales, resalta la atención dada a las mujeres y a las relaciones de género en el recorte de los contextos investigados. Fueron adoptadas diferentes técnicas de recolección de datos: C. B. Reis y Bernardes (2011) y Riscado et al. (2010) utilizaron la técnica de grupos focales; Moura et al. (2009) realizaron entrevistas y observaciones participantes; M. C. P. Sousa et al. (2008), a su vez, adicionaron esas tres técnicas en su investigación.

M. C. P. Sousa et al. (2008) delimitan el contexto de mujeres adultas, viviendo relaciones conyugales estables, en una región de bajos recursos, en la periferia de Teresina/PI. Para identificar la vulnerabilidad de esas mujeres al VIH, los investigadores se ocupan sobre el uso o no del preservativo por las mujeres, las relaciones de género que viven con sus parejas y la actuación del Programa de Salud de la Familia (PSF) en dicho contexto. Perciben que la mayoría de las mujeres no hace uso continuo del preservativo, principalmente, por las dificultades relacionadas con la negociación de esa práctica con la pareja; el preservativo es más fácil de introducirse en la práctica sexual, cuando es vista como un anticonceptivo. En relación a la atención brindada por el PSF a esas mujeres, los investigadores destacan que ésta se restringe al trabajo de educación en salud de la mujer, centrado en la atención prenatal y en las medidas de reducción del cáncer ginecológico, de tal forma que los equipos de salud no incorporan la discusión sobre sexualidad y relaciones de género, lo que agrava la vulnerabilidad de las mujeres en ese contexto.

Siguiendo esa línea, Riscado et al. (2010) realizan un estudio con mujeres en comunidades restantes de Quilombos en Alagoas, entre la cuales encontraron un significativo desconocimiento de la importancia de la utilización del preservativo, así como la resistencia para la adopción de esa práctica y dificultades relacionadas a la necesidad de autorización por parte de la pareja masculina para ello. Para los investigadores, el alto grado de vulnerabilidad de esa mujeres a las ITS/sida está ligado al contexto marcado por condiciones precarias de vida, incidencia elevada de violencia doméstica y de racismo (vivido en diferentes contextos de relaciones sociales e institucionales), dificultades de acceso a los servicios de salud, ausencia de una política de salud más efectiva y de un trabajo educativo en tales comunidades.

El estudio de Moura et al. (2009) también se centra en las mujeres, en un escenario de prostitución y pobreza en el interior de Ceará, en el 
cual la prevención se presenta con diferentes obstáculos. Los investigadores perciben que las prostitutas investigadas enfrentan dificultades para la adquisición de los preservativos, de forma que su utilización queda a cargo del cliente. En general, el preservativo termina siendo usado solamente en las relaciones con los clientes desconocidos y recientes, siendo no utilizado en las relaciones con los clientes antiguos y conocidos, así como con sus parejas estables (a veces casados o en relaciones con otras mujeres). Además, el contexto de sumisión de la prostituta al cliente legitima que él exija la relación sexual sin preservativo, pudiendo inclusive colocar en duda la salud de la profesional si ella no consiente esa práctica.

C. B. Reis y Bernardes (2011), por otro lado, se dedican al estudio en el contexto de las prisiones, e investigan la adopción de estrategias para prevenir la infección y la propagación de las ITS/sida. Perciben que los y las participantes, internos de las prisiones públicas de las ciudades de Mato Grosso do Sul (que interactúan con la comunidad a través de los familiares, de las visitas, de los funcionarios penitenciarios y de las diversas reincidencias) reconocen la importancia de la prevención y señalan los principales métodos preventivos, entre los cuales destacan el uso constante del preservativo como el más eficiente. Sin embargo, existe la tendencia por un uso esporádico, debido a la dificultad para su adquisición, a la falta de orientación del equipo de salud local sobre esa temática y al desinterés de los propios prisioneros y prisioneras, que se justifican por participar de una relación estable con su pareja regular. Las investigadoras hacen una observación sobre la precaria atención de salud de los presos y presas, ligada al prejuicio y a la discriminación de la sociedad.

\section{Estudios de Significados y Sentidos}

En esta vertiente, los artículos se basan en diferentes conceptos y perspectivas teóricas para la comprensión de sentidos y significados atribuidos al uso del preservativo como estrategia de prevención del VIH/sida. Aquí también la característica recurrente es sobre las cuestiones de género para la comprensión de los aspectos rela- cionados al uso del preservativo, principalmente en el ámbito de las relaciones afectivo-sexuales.

Sampaio et al. (2010) y Sampaio et al. (2011) recurren al modelo teórico metodológico de las prácticas discursivas, e investigan la prevención de ITS/sida en el contexto de la atención a adolescentes en Unidades de Salud de la Familia. El primer estudio (Sampaio et al., 2010) discute las producciones de sentido de adolescentes y equipos de salud, al respecto de género y sexualidad y sus implicaciones para la prevención de ITS/sida. Las investigadoras identifican, entre los adolescentes, concepciones machistas y un desconocimiento sobre las formas de prevención de las ITS/sida. Específicamente, destacan producciones de sentido sobre el amor romántico, la fidelidad y monogamia, que están presentes en jóvenes y adultos, hombres y mujeres, que se vinculan a una supuesta protección, lo que establece como innecesario el uso del preservativo en las relaciones conformadas a partir de esos elementos. Entre los profesionales de salud, observan una "significativa dificultad en trabajar la sexualidad en la adolescencia, siendo primordial repensar el discurso biorreduccionista y la educación bancaria, como estrategias de lucha contra las ITS/sida" (p. 173).

Ya el segundo artículo (Sampaio et al., 2011) se centra en la vulnerabilidad de las mujeres jóvenes a las ITS/sida y, en especial, los sentidos atribuidos a las relaciones de género en la configuración de la dificultad que las adolescentes enfrentan para negociar el uso del preservativo con sus parejas. Entre estos sentidos, se destacan la identificación de la iniciativa de proponer el preservativo como atribución del hombre, el asombro relacionado con las chicas que proponen la relación sexual o el uso del preservativo y la "culpabilización" de ellas frente a los casos de ITS o de un embarazo no planificado.

El estudio de Madureira y Trentini (2008b) utiliza la noción de actitud y se detiene en la perspectiva de los hombres heterosexuales en relación al uso del preservativo. Los resultados indican que, en la prevención de ITS/sida, "se entrelazan aspectos vinculados a las creencias, a los mitos, a los estereotipos en salud y a las características de las relaciones hombre-mujer" (p. 
1807). Entre las justificaciones para la ya conocida resistencia masculina al uso del preservativo, las investigadoras identifican la expresión de que es incómodo, que implica una interrupción del progreso del acto sexual, reduce el placer y genera el temor de pérdida de la erección o de un mal desempeño sexual. Por otro lado, se destaca como motivo central del no uso del preservativo, la asociación que se establece entre la práctica preventiva y la desconfianza o la infidelidad.

A partir de esas constataciones, las autoras producen un ensayo (Madureira \& Trentini, 2008a) en el cual relacionan la prevención de ITS/sida con la configuración de las relaciones afectivo-sexuales en el contexto conyugal heterosexual. En ese sentido, elaboran tres modelos de relación, en los cuales se articulan de diferentes formas los elementos amor, deseo, placer y fidelidad. Cada modelo está vinculado a una determinada construcción de la masculinidad y tienen diferentes repercusiones para la adopción de prácticas sexuales protegidas. Aunque esta formulación presente modelos herméticos, que categorizan la participación de las personas en las relaciones, desarrolla hallazgos comunes a otras investigaciones, como el hecho de considerar innecesario el preservativo como método preventivo en las relaciones estables, en las cuales se presume fidelidad; siendo utilizada especialmente en las relaciones casuales, en este caso, extramaritales.

Maksud (2009), a su vez, investiga las representaciones sociales de parejas serodiscordantes en relación a las prácticas sexuales y al uso del preservativo. Entiende que tales representaciones conforman lógicas que, en general, no están acompañadas por el discurso oficial de la prevención. En un intento por "comprender los significados del comportamiento sexual y los sentidos sociales del deseo" (p. 355), la autora identifica construcciones como la relativización de la enfermedad y del riesgo de seroconversión y las dificultades relacionadas a la propia situación del estado civil, como las prácticas sexuales imprevisibles y la justificación manifestada por los hombres, de que no les gusta usar preservativo porque quieren "sentir la piel". En ese sentido, parece ocurrir un proceso de rutinización de la intimidad y una interrupción del sexo seguro.

En esa dirección, R. K. Reis y Gir (2009) realizan un estudio con portadores de $\mathrm{VIH} /$ sida que conviven con parejas serodiscordantes, que son atendidos en un servicio público ambulatorio, de referencia para la atención a portadores de VIH/sida. De los significados identificados en las declaraciones de los participantes, se esboza una idea de la naturalización de la infección del VIH/sida como enfermedad controlable por medicamentos, la creencia de que la terapia antirretroviral y, principalmente, la carga viral indetectable impiden el riesgo de transmisión del virus y un sentimiento de ser invencible que surge con el tiempo de convivencia entre la pareja. Estas construcciones se configuran como factores que interfieren en el mantenimiento del uso del preservativo y, por lo tanto, aumentan la vulnerabilidad de la alianza sexual seronegativa a la infección por el VIH.

Como en los dos estudios anteriores, el artículo de Maliska et al. (2007) problematiza la prevención en el ámbito de las relaciones entre parejas serodiscordantes. En este caso, sin embargo, la discusión se basa en la perspectiva de la feminización de la epidemia del sida y de la "vulnerabilidad de las mujeres". Los resultados indican que las participantes, usuarias de un servicio de atención especializada en ITS/sida, creen estar protegidas en relaciones estables e, incluso después de la infección, enfrentan dificultades para negociar con sus parejas el uso del preservativo. En oposición al requerimiento del uso del preservativo por el equipo de salud, surge la resistencia de los hombres a ese método preventivo, basada en la creencia de que ellos no transmitirán para sus parejas seropositivas una infección más grave de lo que ellas ya tienen, por el "mito" de que la mujer no transmite el VIH para el hombre y por una posible motivación transgresora al respecto de la normativa impuesta por la prevención.

Finalmente, Gomes et al. (2011) se proponen identificar las percepciones de parejas jóvenes heterosexuales de 20 a 27 años, universitarios de un curso de pregrado en Enfermería y sus parejas, acerca del uso del preservativo femenino y los factores que incentivan o dificultan 
la adopción de esa práctica de forma rutinaria. Las investigadoras concluyen que los participantes conocen la eficiencia de ese método, pero resaltan la dificultad de las mujeres para la negociación, la mínima difusión sobre el preservativo femenino y su elevado costo. Sobre su uso, manifiestan, por un lado, practicidad, confiabilidad, placer y, por otro lado, malestar, dolor y apariencia grotesca. La falta de familiaridad y el desconocimiento parecen ser los principales desencadenantes de las dificultades.

\section{Estudios de Actividades}

En primer lugar, presentamos estudios que abordan actividades relacionadas a la prevención del VIH/sida, tomándolas como objetos de investigación o de relato. En seguida, describimos un estudio que utiliza actividades de promoción del uso del preservativo como parte de una investigación específica.

Entre los primeros está la descripción de una intervención con base comunitaria para el control de las ITS/sida en la región amazónica, presentada por Benzaken et al. (2007). Desarrollado en el marco del Sistema Único de Salud, con la participación de investigadores, agentes gubernamentales, profesionales de la salud y comunidad, el programa de intervención abarcó desde la recolección de datos locales (dinámica de la prostitución, venta de preservativos y características comportamentales), hasta las acciones de prevención y atención a la ITS en la Red Pública de Salud y capacitación de trabajadoras del sexo, así como la evaluación de las acciones y del proceso. Se reportan diversos resultados positivos de la experiencia. En lo relacionado al preservativo, se observa, de manera general, un aumento de la venta y del uso entre las trabajadoras del sexo, así como una reducción de las ITS bacterianas y la estabilización de la incidencia de la infección por el VIH/sida y sífilis congénita.

También, en esa dirección, el artículo de Ferraz y Nemes (2009) presenta una evaluación de la implantación de actividades de prevención de ITS/sida en una Unidad de Salud de la Familia. Según las autoras, el perfil tecnológico de la unidad investigada es semejante a los servicios tradicionales de atención básica en el Brasil, presentando limitado potencial de concretización del principio de integralidad. En ese sentido, las actividades de prevención implantadas, entre las cuales consta la distribución de preservativos, se muestran fragmentadas y "vacías de importantes sentidos tecnológicos, como el diálogo y la atención a la singularidad de los usuarios" (p. S249).

El estudio de Borba (2011) se refiere al análisis de las intervenciones, en las que activistas de una organización no gubernamental distribuyen preservativos entre travestis que se prostituyen. Con énfasis en la relación entre el lenguaje y la construcción interaccional de identidades sociales, el investigador examina las dinámicas discursivas que emergen en las interacciones entre mediadoras y travestis y aboga a favor de la importancia y la utilidad de la comprensión de estos elementos en el trabajo de prevención entre los grupos considerados marginados y en la lucha contra la propagación de las ITS/sida.

A. A. Sousa et al. (2009) presentan un breve relato del proyecto que realizan trimestralmente en Suzano/SP. Se trata de una velada temática destinada a artistas, profesores y miembros de la comunidad en general, en el cual actividades artísticas y musicales son ligadas a la distribución de preservativos y materiales informativos, que fomentan discusiones sobre la sexualidad, a la luz de las prácticas sexuales seguras. El evento ha generado un fomento por la lectura y el arte erótico, la difusión y la ampliación del acceso a los servicios de salud.

A su vez, el estudio de Albuquerque y Villela (2011), sobre el preservativo femenino, realizado con mujeres, en un servicio de Salud de la Familia, presenta la intervención como parte de la investigación. En este caso, la recolección de los datos propiamente dicha, se articula con actividades educativas, la demostración del insumo en el consultorio de enfermería y su uso en el domicilio. Los resultados muestran que, después del susto inicial con el preservativo femenino, la mayoría de usuarias relata una impresión positiva y manifiestan dificultades en el manejo e introducción, debido a la excesiva lubrificación. Aunque el foco de la investigación sea la anticoncepción, la prevención de ITS aparece como 
motivo relevante en la elección de este método. De manera general, sin embargo, la adopción del preservativo femenino se enfrenta con dificultades de negociación con la pareja.

\section{Estudios de Revisión de la Literatura}

En el grupo de artículos analizados, sólo dos se encajan en esta vertiente. El artículo de Brisighelli et al. (2009) presenta de forma resumida una revisión sobre la eficacia del preservativo como método de prevención de ITS. A partir de los estudios levantados, los autores resaltan que el preservativo no se configura como una barrera completamente eficaz, toda vez que su material es permeable a pequeños virus, que éste no cubre toda la región perineal y que el transporte y almacenamiento pueden alterar su calidad. Además, la falta de conocimiento y familiaridad con su uso correcto es un factor importante de disminución de la eficacia.

Por otro lado, la revisión producida por Rebello et al. (2011) enfatiza la relación entre hombres y la prevención del sida. A partir de los estudios encontrados, los autores señalan, entre otros aspectos, la centralidad del preservativo en la prevención. Sin embargo, ese elemento aparece en la literatura especialmente a partir de la problematización de la aceptación de su uso por parte de los hombres. En ese sentido, los autores resaltan el consenso de que los motivos para no usar el preservativo están estructurados a partir de los modelos de creencias presentes en el imaginario social. A lo largo de la revisión, son identificadas diferentes construcciones características de esos modelos: las relaciones de poder entre el hombre y la mujer; la asociación del preservativo con el sexo ilícito y; por lo tanto, con la infidelidad; la idea de que el preservativo no combina con el matrimonio; de que el preservativo puede no aplicarse en las relaciones que envuelven compromiso efectivo; la creencia de que el uso del preservativo puede causar daño al hombre, ya que retiene algo que debería dejarse libre, y a la mujer porque impide que su útero se moje con el semen; la creencia de que las mujeres no pueden transmitir el VIH; la negativa a utilizar el preservativo como demostración de que no se teme al riesgo; la asociación entre la satisfacción en el sexo anal y la identidad de los hombres que hacen sexo con hombres. Argumentan, finalmente, que esta discusión progresa a medida en que se articula el papel de tal medida preventiva en sí con los sentidos asociados al preservativo.

\section{A Modo de Discusión: Aspectos de la Literatura y Consideraciones sobre las Vertientes}

A pesar de la diversidad de los estudios acerca del uso del preservativo como estrategia de prevención del VIH/sida, se destacan algunos aspectos en esta literatura, en particular, la atención dada a los jóvenes y a las cuestiones de género. Los estudios en esas direcciones pueden ser comprendidos a la luz del énfasis dado a los grupos de jóvenes en las políticas de prevención (Paiva et al., 2008) y de la centralidad de las discusiones sobre la "negociación" del uso del preservativo entre las parejas (Madureira \& Trentini, 2008a, 2008b). Se trata, aún, de dos aspectos de naturalezas diferentes.

El primero se dirige a un segmento poblacional y es predominante entre los estudios más cuantitativos. Podemos notar que el grupo denominado de jóvenes (o adolescentes) es definido de distintos modos en los estudios, con diferentes recortes de edades y abarcando participantes dentro y fuera del sistema educativo.

Con respecto a los otros grupos presentes en la literatura investigada, resaltamos la escasez de estudios que discuten el uso del preservativo entre $\mathrm{HSH}$, usuarios de drogas inyectables y profesionales del sexo, grupos en los cuales la epidemia del VIH y sida en el Brasil, se mantiene concentrada desde sus inicios (Malta et al., 2010). En este sentido, destacamos, que, entre los hombres jóvenes, los gays han demostrado ser el grupo más afectado por el VIH en los últimos años (MS, 2011). De la misma forma, son pocos los trabajos que engloban el contexto de la prostitución y no son incluidos los chicos que se prostituyen. También es poco presente o ausente la consideración de otros marcadores sociales de la diferencia en la definición de los participantes y en el delineamiento de las investigaciones, 
como raza/etnia (son escasas o inexistentes investigaciones con poblaciones negras, indígenas, etc.).

El segundo aspecto es temático, dice respecto a las relaciones de género, que han configurado algunos retos para la adopción del uso del preservativo, debido al carácter relacional de las prácticas sexuales, la dimensión del poder que se articula a las relaciones de género y los valores culturales asociados a las construcciones de masculinidades y feminidades. Este aspecto aparece más claramente en las investigaciones de diseño cualitativo; en aquellas que discuten directamente las relaciones entre parejas como en los estudios realizados con hombres o con mujeres específicamente. De modo incipiente, las relaciones de género se articulan a otros aspectos sociales relevantes, de forma que podemos encontrarlas en estudios con parejas serodiscordantes, con mujeres "quilombolas", pobres, jóvenes y prostitutas.

La emergencia de las relaciones de género como un importante determinante de la epidemia del VIH/sida acontece a partir de la identificación de la tendencia de feminización de la epidemia ocurrida desde el inicio de la década de 1990 con el crecimiento del número de casos de sida en el Brasil y en el mundo (MS, 2009). En esta esfera, es importante prestar atención a la complejidad de tales configuraciones sociales, bajo el riesgo de la reproducción de constantes clichés en las discusiones de género, que obstaculizan la reflexión sobre los matices y circularidades características de la relación de género con sexualidad $\mathrm{y}$, específicamente, como el uso del preservativo. Recordamos, así, la crítica y relativización de la idea de negociación del uso del preservativo en el campo de las relaciones desiguales de género hechas en la década de 1990 por R. M. Barbosa, Villela y Uziel (1995) que cuestionaban cierta simplificación de la compleja ecuación establecida entre las ideas de negociación y adopción o no de prácticas sexuales más seguras.

En relación a otros temas, abordados de forma menos significativa o ausente en el conjunto de estudios analizados, sería inagotable la lista de asuntos que pueden y merecen consideración en el ámbito del tema investigado. Destacamos, entre ellas, la falta de reflexiones en la producción académica nacional al respecto de "la fatiga del preservativo" y la necesidad de profundizar en las discusiones sobre la actuación de los servicios de salud en ese contexto, cuya relevancia está marcada por el reconocimiento de la dimensión programática de la vulnerabilidad al VIH/ sida y, en este sentido, el apoyo disponible para la prevención. Por otra parte, y principalmente, en los estudios de significados y sentidos, sería fructífera una reflexión más profunda sobre la medicalización del uso del preservativo y del discurso preventivo ${ }^{7}$, así como la investigación de la posible aproximación de ese discurso con la dimensión de lo erótico sugerida, por ejemplo, por Parker (1994).

Al respecto de las seis vertientes de los estudios, resaltamos que la categorización realizada no agota las posibilidades de analizar el conjunto de textos utilizado. Por otra parte, la categorización de las vertientes no es totalmente homogénea, considerando que algunos artículos, aunque se ajusten mejor en un tipo de estudio, pueden presentar características de otra vertiente. Como ocurre con el artículo de Cruzeiro et al. (2010), del grupo de los estudios epidemiológicos, que maneja, sin embargo, una lógica típica de los estudios de conocimientos y comportamientos. Esa intersección parece suceder más claramente en relación al debate de los sentidos y significados, presente, de forma secundaria, en los artículos de Ribeiro et al. (2011), de los estudios epidemiológicos; de M. C. P. Sousa et al. (2008), de los estudios de contextos especificos; de Matos et al. (2009) y de Saldanha et al. (2008), de los estudios de conocimientos y comportamientos.

A pesar que todos los estudios analizados tienen en común el propósito de producir conocimiento útil para el combate del $\mathrm{VIH} / \mathrm{sida}$ en el campo de la prevención, específicamente a través del uso del preservativo, cada vertiente presenta una lógica particular a fin de abordar la cuestión y un tipo específico de conocimiento

7 "Medicalización del uso del preservativo y del discurso preventivo" es comprendida aquí en el sentido adoptado en las discusiones sobre "medicalización social”, revisar: Tesser (2006). 
producido. Pensando de manera amplia, podemos resaltar la complementariedad de estos enfoques diferentes, ya que todos los estudios añaden informaciones a la literatura. Sin embargo, es importante estar atentos a los límites en que esas formas de producción de conocimiento se han estancado y a los cuidados necesarios tanto en la conducción de investigaciones con determinados diseños, como en la lectura y uso de las conclusiones presentadas.

En este sentido, vale la pena puntualizar que los estudios epidemiológicos poseen reconocida relevancia en cuanto al alcance de los datos producidos (por ejemplo, son ellos los que posibilitan una estimación del uso del preservativo en la población) y su contribución en la indicación de prioridades para la elaboración de acciones y políticas de prevención. Sin embargo, la construcción de dicho conocimiento implica en sucesivos procesos de abstracción conceptual, que le garantizan un manejo formal y matemático de gran precisión, a expensas de una desviación de aspectos de la realidad, fundamentales para que pensemos en la prevención (Ayres, 2002). La historia de la producción de conocimientos en el campo del sida ha demostrado el peligro de esta retirada, principalmente, en la posibilidad de tener una asociación probabilística [por ejemplo, la indicación, presente en la investigación de Berquó et al. (2008), de que personas de religión pentecostal usan menos preservativos que aquellas sin religión o adeptas de otras religiones] de modo que lleve a generalizar determinada característica, produciendo identidades y etiquetando personas $\mathrm{y}$, en estos términos, orientar el diseño y la ejecución de acciones preventivas (Ayres et al., 2006).

Ya los estudios de conocimientos y comportamientos, a su vez, representan un intento por identificar $\mathrm{y} / \mathrm{o}$ estructurar informaciones $\mathrm{y}$ prácticas útiles para la prevención del VIH/sida. Parecen tener como horizonte la(s) técnica(s) relevante(s) para el trabajo preventivo; por ejemplo, buscan identificar qué informaciones son menos conocidas y necesitan ser más difundidas o qué orientaciones son más efectivas en actividades educativas. Sin embargo, esta forma de producir conocimiento puede incidir en la adopción de criterios naturalizados o normativos al respecto de las prácticas sexuales, al tomar, como parámetro, conocimientos y comportamientos considerados correctos independientemente de los contextos de intersubjetividad en los cuales las identidades personales, los valores y las prácticas son concreta y dinámicamente constituidos.

Como señala Paiva (2000), la concepción comportamental de la prevención, a pesar de haber representado una abertura en el trabajo con las informaciones y orientaciones al respecto de las prácticas sexuales (más o menos) seguras, especialmente, en relación al uso del preservativo, tiende a ignorar el contexto social, tomando el cambio comportamental como una responsabilidad individual y un proceso intencional de los sujetos "persuadidos" por los técnicos de su necesidad.

De forma particular, los estudios de esta vertiente que identifican que la mayoría de jóvenes tienen conocimiento sobre el sida y los medios de prevención, especialmente el preservativo (Alves \& Lopes, 2008; Leite et al., 2007; Marta et al., 2008), nos llevan a conclusiones favorables al respecto de la difusión de informaciones y orientaciones sobre la prevención y de los trabajos de educación para la sexualidad. Este panorama; sin embargo, es contradictorio a investigaciones como la de Sampaio et al. (2010), de los estudios de significados y sentidos, que identifican un constante desconocimiento de chicas y chicos sobre las ITS y la prevención y, por otro lado, la creencia de los profesionales de los servicios de salud de que los jóvenes tienen esas informaciones, a pesar de las cuales tienden a no mantener comportamientos preventivos por irresponsabilidad, lo que imposibilitaría el trabajo de prevención con ese público. Podemos señalar, en este sentido, la necesidad de distinguir el acceso a la información de una real posibilidad de comunicación entre los sujetos involucrados en la práctica preventiva con miras a la transformación de los contextos de intersubjetividad que conforman la vulnerabilidad al VIH/sida (Ayres, França, Calazans, \& Saletti, 2003).

Los estudios de contextos especificos y los estudios de significados y sentidos, regulados 
por una lógica comprensiva sobre el uso del preservativo, parecen responder a la percepción de que la adquisición del conocimiento sobre las ITS/sida y el uso del preservativo no es suficiente para la adopción del sexo protegido (referida, por ejemplo, por Alves \& Lopes, 2008), ya que tales prácticas no están desfasadas de los contextos en que ocurren y de las construcciones sociales que en ellas operan. En ese sentido, más allá del uso del preservativo y del (re)conocimiento de su importancia, estos estudios permiten el avance del conocimiento y de la reflexión acerca de las implicaciones de esa práctica para los sujetos, de lo que ella representa y acciona en determinadas situaciones.

Más aún, el considerar contextos específicos y la construcción de significados y sentidos, por sí solos, no garantizan producir una totalidad comprensiva útil sobre las dificultades y posibilidades acerca del uso del preservativo como método de prevención de VIH/sida. Y, en esa dirección, existe el peligro de incurrir en la falacia de abordar tales aspectos simplemente como instrumentos para "convencer" mejor a las personas sobre el uso del preservativo, sin siquiera, buscar una fusión de horizontes ${ }^{8}$ con tales contextos y construcciones.

Todavía, sobre los estudios de contextos específicos, recordamos que, en general, ellos operan con una lógica de que los sujetos son comprendidos como colectivos, en función de las condiciones del entorno. En este caso, es necesario estar atentos para no perder la perspectiva de la subjetividad y del modo singular como las personas se relacionan con tales condiciones. Es particularmente importante que, en el proceso de comprensión, podamos observar como los diferentes contextos intersubjetivos conforman identidades y horizontes prácticos que son centrales para establecer diálogos que puedan efectivamente propiciar cambios en las relaciones y reducción de vulnerabilidades.

Los estudios de actividades, tienen su relevancia demarcada por el registro de experien-

8 Para una discusión al respecto del concepto de fusión de horizontes, revisar Ayres (2008). cias y por la posibilidad de articulación de la investigación con intervenciones. Esto es especialmente importante en un campo como el de la prevención de ITS/sida, que mantiene gran aproximación con la práctica y cuya actuación, en especial las acciones de promoción del uso del preservativo, se encuentran en construcción, ya que todavía se imponen desafíos significativos y lo que tenemos acumulado son algunas lecciones, como muestran Ayres (2002) y Paiva (2000).

Vale la pena resaltar, en el universo estudiado, la poca expresividad de las publicaciones dirigidas al desafío, nada insignificante, del "cómo hacer" referente a las prácticas de promoción del uso del preservativo. Considerando, entre los estudios de actividades, únicamente los relatos y análisis de experiencias, notamos que son pocas las iniciativas que se dedican a describir y/o evaluar proposiciones tecnológicas al respecto de cómo promover el uso del preservativo en determinados contextos. Nos parece que éste pueda ser un campo más explorado, basado en la descripción de innovaciones tecnológicas sobre las prácticas articuladas a la densa reflexión sobre fundamentos teóricos y las dificultades/potencialidades identificadas en diferentes contextos y con diferentes grupos poblacionales. En ese sentido, considerando la centralidad del preservativo en la política de prevención de ITS/ sida en el contexto nacional, se trata de un tipo de producción fundamental cuando se refiere a un universo de prácticas en salud.

Los estudios de revisión, de forma general, son oportunidades para levantar una síntesis y evaluación del conocimiento producido sobre determinado tema. En relación al uso del preservativo como estrategia de prevención de ITS/ sida, como vemos, estos estudios son escasos en los últimos cinco años. Considerando que los dos trabajos identificados en esta vertiente se refieren a recortes temáticos específicos (eficacia del preservativo y prevención y hombres), notamos la ausencia de un trabajo más amplio de sistematización de los estudios sobre el uso del preservativo como método de prevención, tema central de la política de enfrentamiento de las ITS/sida en Brasil. 
En dirección por superar esa laguna, el presente ensayo representa un intento de creación de un panorama crítico de los estudios sobre el tema, que contribuya con la comprensión al respecto de cómo hemos pensado el uso del preservativo y la prevención del VIH/sida y cómo hemos operacionalizado teórica y metodológicamente las investigaciones y prácticas en ese campo. En este sentido, pretendemos que el estudio pueda viabilizar nuevos análisis y abordajes sobre el tema.

Es evidente que este estudio se presenta con limitaciones relevantes, tales como el recorte temporal en la selección de los artículos y los criterios que no pudieron ser incorporados al análisis, como la caracterización de autores y la vinculación de posibles grupos de investigadores. Estos aspectos, podrían, por ejemplo, viabilizar la problematización de lo que nos pareció ser una concentración de las publicaciones sobre el tema en determinadas áreas, notoriamente, la Salud Pública y la Enfermería, destacándose escasez de artículos en revistas científicas de Psicología. La concentración de dichas publicaciones en el campo restringido a esas áreas de las Ciencias de la Salud va de encuentro con la comprensión de que las acciones de reducción de la vulnerabilidad a las ITS/sida no deben limitarse a la esfera institucional de la salud, debiendo ampliarse su campo de acción de forma interdisciplinar y intersectorial con miras a la transformación de los contextos de vulnerabilidad (Ayres et al., 2003). Sobre la Psicología, todavía podríamos considerar, especialmente, que entre los autores de los artículos analizados, se encuentran investigadores/profesionales con formación en Psicología y que algunos artículos se basan en referenciales teóricos originarios de la Psicología9. En la ausencia de un análisis sistemático al respecto, cabe únicamente cuestionarnos por qué los psicólogos que investigan y estudian la prevención de ITS/sida, han buscado o encontrado más espacio en revistas de otras áreas.

9 Por ejemplo, las investigaciones sobre comportamientos o cambios comportamentales y sobre prácticas discursivas, presentadas en la sección de Resultados.
Además, la no ampliación del campo de esta investigación a través de la utilización de otras bases de datos configura una limitación en función de las restricciones encontradas en el portal utilizado para la búsqueda de artículos, principalmente, en lo referente a los mecanismos de búsqueda y a la recuperación de los artículos a partir de los links disponibles en el portal.

Por último, recordamos que, dada la gran cantidad de estudios realizados acerca de temas relacionados con el uso de preservativos, optamos por direccionar el foco de este trabajo para la prevención del VIH/sida, dejando de lado aspectos relevantes, específicos de las discusiones relacionadas con la anticoncepción y la prevención de otras ITS.

\section{Consideraciones Finales}

El análisis comprendido en este artículo nos permite elaborar algunas conclusiones al respecto de la producción académica sobre el uso del preservativo como estrategia de prevención del $\mathrm{VIH} /$ sida. En primer lugar, la literatura del área puede ser descrita como concentrada en la investigación de algunos grupos de participantes y en la discusión de algunos temas en especial, dejando de lado sujetos, contextos y cuestiones que se muestran importantes en el enfrentamiento de la epidemia del sida y en la adopción de prácticas preventivas. Esto va de encuentro con la impresión de que se trata de una literatura amplia y diversa, que podemos tener al calcular la cantidad de estudios publicados que abordan el asunto. En este sentido, se hace necesaria la producción de nuevos estudios que analicen y construyan panoramas acerca de esa producción, de forma a delinear caminos que precisan ser trazados o fortalecidos en la investigación en el campo de la prevención del VIH/sida.

Otra característica observada es que la literatura estudiada se presenta de forma difusa en relación a las lógicas de producción del conocimiento. A pesar del valor inherente a una producción que comprende diferentes aportes teórico-metodológicos, encontramos un enmarañado de enfoques y orientaciones, que en algunos momentos, parece confuso. Es lo que vemos al identificar la permanencia de estudios que se basan 
en un enfoque comportamental de la prevención y la articulan con el cuadro de la vulnerabilidad que, en la historia de los conceptos operacionales de las investigaciones en el campo del sida, marca la crítica y la superación de la perspectiva individualista de ese primer abordaje.

Encontramos diversas referencias sobre la vulnerabilidad al VIH en el conjunto de estudios analizados, abarcando desde utilizaciones más superficiales de los términos propios de ese cuadro hasta apropiaciones más substanciales de dicha referencia, pasando por las articulaciones hechas con la noción de riesgo o con el enfoque comportamental. Presumimos, de un lado, el gran alcance de las formulaciones y de la terminología del cuadro de la vulnerabilidad y, de cierto modo, su legitimidad [reconocida, como visto anteriormente, por la propia política pública nacional (MS, 2009)]. De otro lado, notamos la multiplicidad de orientaciones en la producción de conocimiento sobre el asunto en cuestión, lo que indica la necesidad de un mayor debate y madurez epistemológica y metodológica tanto en relación al cuadro de la vulnerabilidad, como al conjunto de referenciales utilizados en los estudios sobre el uso del preservativo como estrategia de prevención del VIH/sida.

Vemos en dicha madurez una tarea intransferible, un compromiso histórico necesario para el enfrentamiento de la epidemia del sida, en el sentido de: (a) reconocer los grupos poblacionales más afectados; (b) buscar comprender sus complejas susceptibilidades socialmente configuradas; (c) diseñar enfoques vigorosos, creativos y potentes, capaces de envolver personas y grupos para que se apropien y se movilicen de forma auténtica para encontrar alternativas prácticas que posibiliten superar las condiciones que conforman las vulnerabilidades.

\section{Referencias}

Adam, B. D., Husbands, W., Murray, J., \& Maxwell, J. (2005). AIDS optimism, condom fatigue, or self-esteem? Explaining unsafe sex among gay and bisexual men. The Journal of Sex Research, 42(3), 238-248.
Albuquerque, G. A., \& Villela, W. V. (2011). Uso do preservativo feminino como método contraceptivo: Experiências de mulheres em uma Unidade Básica de Saúde no município de Juazeiro do Norte - CE. Revista de APS - Atenção Primária à Saúde, 14(2), 185-196.

Alves, A. S., \& Lopes, M. H. B. M. (2008). Conhecimento, atitude e prática do uso de pílula e preservativo entre adolescentes universitários. Revista Brasileira de Enfermagem, 61(1), 11-17.

Ayres, J. R. C. M. (2002). Práticas educativas e prevenção de HIV/Aids: Lições aprendidas e desafios atuais. Interface - Comunicação, Saúde, Educação, 6(11), 11-24.

Ayres, J. R. C. M. (2008). Para comprender el sentido práctico de las acciones de salud: contribuciones de la hermenéutica filosófica. Salud Colectiva, 4, 159-172.

Ayres, J. R. C. M., Calazans, G. J., Saletti, H. C., Filho, \& França, I., Jr. (2006). Risco, vulnerabilidade e práticas de prevenção e promoção da saúde. In G. W. S. Campos, M. C. S. Minayo, M. Akerman, M. Drumond Jr., \& Y. M. Carvalho, Tratado de Saúde Coletiva (pp. 375-417). São Paulo, SP: Hucitec.

Ayres, J. R. C. M., França, I., Jr., Calazans, G. J., \& Saletti, H. C., Filho. (2003). O conceito de vulnerabilidade e as práticas de saúde: Novas perspectivas e desafios. In D. Czeresnia (Org.), Promoção da saúde: Conceitos, reflexões e tendências (pp. 121-143). Rio de Janeiro, RJ: Editora da Fundação Oswaldo Cruz.

Ayres, J. R. C. M., Paiva, V., \& França, I., Jr. (2011). From Natural History of Disease to Vulnerability: Changing concepts in contemporary public health. In R. Parker, \& M. Sommer (Eds.), Routledge Handbook in Global Public Health (pp. 98-107). New York: Routledge.

Barbosa, R. M., Villela, W. V., \& Uziel, A. P. (1995). Entre a vontade e a necessidade: Negociação sexual em tempos de aids. Physis - Revista de Saúde Coletiva, 5(1), 99-107.

Barbosa, S. M., Costa, P. N. P., \& Vieira, N. F. C. (2008). Stages of change in parents' discussions with their children about HIV/Aids prevention. Revista Latino-Americana de Enfermagem, 16(6), 1019-1024.

Benzaken, A. S., Galbán Garcia, E., Sardinha, J. C. G., Pedrosa, V. L., \& Paiva, V. (2007). Intervenção de base comunitária para a prevenção das 
DST/Aids na região amazônica, Brasil. Revista de Saúde Publica, 41(Supl. 2), 118-126.

Berquó, E., Barbosa, R. M., Lima, L. P., \& Grupo de Estudos em População, Sexualidade e Aids. (2008). Uso do preservativo: Tendências entre 1998 e 2005 na população brasileira [Trends in condom use: Brazil 1998 and 2005]. Revista de Saúde Pública, 42(Supl. 1), 34-44.

Borba, R. (2011). Interconexões entre Linguística Aplicada e práticas de atenção à saúde: Linguagem e identidades na prevenção de DSTs/Aids entre travestis profissionais do sexo. Physis Revista de Saúde Coletiva, 21(4), 1369-1400.

Brisighelli, A. B., Neto, Araújo, A. C., Doher, M. P., \& Haddad, M. A. (2009). Revisão sobre a eficácia do preservativo em relação à proteção contra doenças sexualmente transmissíveis e gestação. Diagnóstico e Tratamento, 14(3), 123-125.

Carvalho, A. L. S., Bezerra, S. J. S., Leitão, N. M. A., Joca, M. T., \& Pinheiro, A. K. B. (2007). Porte, acondicionamento e utilização de preservativo masculino entre jovens de Fortaleza: Um estudo descritivo. Online Brazilian Journal of Nursing, 6 .

Costa, L. C., Rosa, M. I., \& Battisti, I. D. E. (2009). Prevalence of condom use and associated factors in a sample of university students in southern Brazil. Cadernos de Saúde Publica, 25(6), 1245-1250.

Cruzeiro, A. L. S., Souza, L. D. M., Silva, R. A., Pinheiro, R. T., Rocha, C. L. A., \& Horta, B. L. (2010). Comportamento sexual de risco: Fatores associados ao número de parceiros sexuais e ao uso de preservativo em adolescentes. Ciência \& Saúde Coletiva, 15(Supl. 1), 1149-1158.

Ferraz, D. A. S., \& Nemes, M. I. B. (2009). Avaliação da implantação de atividades de prevenção das DST/AIDS na atenção básica: Um estudo de caso na Região Metropolitana de São Paulo, Brasil. Cadernos de Saúde Publica, 25(Supl. 2), s240-s250.

Gomes, V. L. O., Fonseca, A. D., Jundi, M. G., \& Severo, T. P. (2011). Percepções de casais heterossexuais acerca do uso da camisinha feminina. Escola Anna Nery Revista de Enfermagem, 15(1), 22-30.

Joint United Nations Programme on HIV/AIDS. (2012). UN Secretary-General issues recommendations to bolster AIDS response in order to meet 2015 targets [Press release]. Recuperado el 10 mayo, 2012, de http://www.unaids. org/en/media/unaids/contentassets/documents/ pressrelease/2012/04/20120430_PR_SG_Report_en.pdf

Kalckmann, S., Farias, N., \& Carvalheiro, J. R. (2009). Avaliação da continuidade de uso do preservativo feminino em usuárias do Sistema Único de Saúde em unidades da região metropolitana de São Paulo, Brasil. Revista Brasileira de Epidemiologia, 12(2), 132-143.

Kalichman, A. O. (1993). Vigilância epidemiológica de AIDS: Recuperação histórica de conceitos e práticas (Disertación de Maestria, Faculdade de Medicina, Universidade de São Paulo, SP, Brasil).

Laroque, M. F., Affeldt, Â. B., Cardoso, D. H., Souza, G. L., Santana, M. G., \& Lange, C. (2011). Sexualidade do idoso: Comportamento para a prevenção de DST/AIDS [Sexuality of the elderly: Behavior for the prevention of STD/AIDS]. Revista Gaucha de Enfermagem, 32(4), 774-780.

Leite, M. T. F., Costa, A. V. S., Carvalho, K. A. C., Melo, R. L. R., Nunes, B. M. T. V., \& Nogueira, L. T. (2007). Saber e prática contraceptiva e prevenção de DST/HIV/AIDS em universitários da área da saúde. Revista Brasileira de Enfermagem, 60(4), 434-438.

Lima, F. S. S., Silva, M. J. G., Godoi, A. M. M., \& Merchán-Hamann, E. (2008). Homens que fazem sexo com homens: Uso dos serviços de saúde para prevenção/controle de HIV/AIDS em Brasília-DF. Comunicação em Ciências da Saúde, 19(1), 25-34.

Madureira, V. S. F., \& Trentini, M. (2008a). Relações de poder na vida conjugal e prevenção da AIDS. Revista Brasileira de Enfermagem, 61(5), 637642.

Madureira, V. S. F., \& Trentini, M. (2008b). Da utilização do preservativo masculino à prevenção de DST/aids. Ciência \& Saúde Coletiva, 13(6), 1807-1816.

Maksud, I. (2009). O discurso da prevenção da Aids frente às lógicas sexuais de casais sorodiscordantes: Sobre normas e práticas. Physis - Revista de Saúde Coletiva, 19(2), 349-369.

Maliska, I. C. A., Souza, M. I. C., \& Silva, D. M. G. V. (2007). Práticas sexuais e o uso do preservativo entre mulheres com HIV/aids. Ciência, Cuidado e Saúde, 6(4), 471-478.

Malta, M., Magnanini, M. M. F., Mello, M. B., Pascom, A. R. P., Linhares, Y., \& Bastos, F. 
I. (2010). HIV prevalence among female sex workers, drug users and men who have sex with men in Brazil: A systematic review and meta-analysis. BMC Public Health, 10(317).

Marta, C. B., Francisco, M. T. R., Martins, E. R. C., \& Clos, A. C. (2008). A prevenção da AIDS entre estudantes ao iniciar o curso de graduação em Enfermagem. Revista de Enfermagem, 16(4), 557-561.

Maschio, M. B. M., Balbino, A. P., Souza, P. F. R., \& Kalinke, L. P. (2011). Sexualidade na terceira idade: Medidas de prevenção para doenças sexualmente transmissíveis e AIDS. Revista Gaúcha de Enfermagem, 32(3), 583-589.

Matos, E. B., Veiga, R. T., \& Reis, Z. S. N. (2009). Intenção de uso de preservativo masculino entre jovens estudantes de Belo Horizonte: Um alerta aos ginecologistas. Revista Brasileira de Ginecologia \& Obstetrícia, 31(11), 574-580.

Ministério da Saúde. (2009, jul.). Plano Integrado de enfrentamento da feminização da Epidemia de Aids e outras DST [Versão revisada]. Brasília, DF: Autor. Recuperado el 15 mayo, 2012, de http://sistemas.aids.gov.br/feminizacao/sites/default/files/PlanoIntegrado-2009.pdf

Ministério da Saúde. (2011). Boletim Epidemiológico: Aids-DST [Versão preliminar]. Brasília, DF: Autor.

Moura, A. D. A., Lima, G. G., Farias, L. M., Feitoza, A. R., \& Barroso, M. G. T. (2009). Prostituição x DST/Aids: Um estudo descritivo com perspectiva de práticas de prevenção. DST - Jornal Brasileiro de Doenças Sexualmente Transmissiveis, 21(3), 143-148.

Nicolau, A. I. O., \& Pinheiro, A. K. B. (2010). Knowledge, attitude and practice of women prisoners on male and female condoms - Preview note. Online Brazilian Journal of Nursing, 9(1).

Oliveira, N. S., Moura, E. R. F., Guedes, T. G., \& Almeida, P. C. (2008). Conhecimento e promoção do uso do preservativo feminino por profissionais de unidades de referência para DST/HIV de Fortaleza-CE: O preservativo feminino precisa sair da vitrine. Saúde e Sociedade, 17(1), 107-116.

Organización de la Naciones Unidas. (2011). The Secretary-General Message on World Aids Day (1 December 2011). Recuperado el 10 mayo, 2012, de http://www.unaids.org/en/media/unaids/contentassets/documents/speech/2011/20111128_ UNSG_message_WAD2011_en.pdf
Ostrow, D. G., Silverberg, M. J., Cook, R. L., Chmiel, J. S., Johnson, L., Li, X., \& Jacobson, L. P. (2008). Prospective Study of Attitudinal and Relationship Predictors of Sexual Risk in the Multicenter AIDS Cohort Study. AIDS and Behavior, 12, 127-138.

Paiva, V. (2000). Fazendo arte com camisinha. São Paulo, SP: Summus.

Paiva, V., Calazans, G., Venturi, G., Dias, R., \& Grupo de Estudos em População, Sexualidade e Aids. (2008). Idade e uso de preservativo na iniciação sexual de adolescentes brasileiros. $R e$ vista de Saúde Pública, 42(Supl. 1), 45-53.

Paiva, V., Venturi, G., França, I., Jr., \& Lopes, F. (2003). Uso de preservativos: Pesquisa Nacional MS / IBOPE, Brasil. Recuperado el 2 junio, 2012, de http://nepaids.vitis.uspnet.usp.br/wp-content/uploads/2010/04/artigo_preservativo. pdf

Parker, R. G. (1994). A construção da solidariedade: AIDS, sexualidade e política no Brasil. Rio de Janeiro, RJ: Relume-Dumará.

Petchesky, R. P. (1999). Direitos sexuais: Um novo conceito na prática política internacional. In R. M. Barbosa \& R. Parker (Orgs.), Sexualidades pelo avesso: Direitos, identidades e poder. Rio de Janeiro, RJ: Instituto de Medicina Social, Universidade Estadual do Rio de Janeiro.

Rebello, L. E. F. S., Gomes, R., \& Souza, A. C. B. (2011). Homens e a prevenção da aids: Análise da produção do conhecimento da área da saúde. Interface - Comunicação, Saúde, Educação, 15(36), 67-78.

Reis, C. B., \& Bernardes, E. B. (2011). O que acontece atrás das grades: Estratégias de prevenção desenvolvidas nas delegacias civis contra HIV/ AIDS e outras doenças sexualmente transmissíveis. Ciência \& Saúde Coletiva, 16(7), 33313338.

Reis, R. K., \& Gir, E. (2009). Vulnerabilidade ao HIV/AIDS e a prevenção da transmissão sexual entre casais sorodiscordantes. Revista da Escola de Enfermagem da USP, 43(3), 662-669.

Ribeiro, K. C. S., Silva, J., \& Saldanha, A. A. W. (2011). Querer é poder? A ausência do uso de preservativo nos relatos de mulheres jovens. DST - Jornal Brasileiro de Doenças Sexualmente Transmissiveis, 23(2), 84-89.

Riscado, J. L. S., Oliveira, M. A. B., \& Brito, Â. M. B. B. (2010). Vivenciando o racismo e a violên- 
cia: Um estudo sobre as vulnerabilidades da mulher negra e a busca de prevenção do HIV/aids em comunidades remanescentes de Quilombos, em Alagoas. Saúde e Sociedade, 19(Supl. 2), 96108.

Saldanha, A. A. W., Carvalho, E. A. B., Diniz, R. F., Freitas, E. S., Félix, S. M. F., \& Silva, E. A. A. (2008). Comportamento sexual e vulnerabilidade à AIDS: Um estudo descritivo com perspectiva de práticas de prevenção. DST - Jornal Brasileiro de Doenças Sexualmente Transmissiveis, 20(1), 36-44.

Sampaio, J., Paixão, L. A., Andrade, P. M., \& Torres, T. S. (2010). Gênero, sexualidade e práticas de prevenção das DST/Aids: Produções discursivas de profissionais da saúde da família e de adolescentes do Vale do São Francisco. Psicologia: Teoria e Prática, 12(2), 173-187.

Sampaio, J., Santos, R. C., Callou, J. L. L., \& Souza, B. B. C. (2011). Ele não quer com camisinha e eu quero me prevenir: Exposição de adolescentes do sexo feminino às DST/aids no semi-árido nordestino. Saúde e Sociedade, 20(1), 171-181.

Sousa, A. A., Lucareski, M. A., Brizolara, R. V., Bortoletto, C. C. P., \& Pinto, W. (2009). Pavio Erótico: Uma experiência de Suzano na prevenção das DST/HIV/Aids e fomento da arte erótica. Saúde e Sociedade, 18(Supl. 1), 63-65.
Sousa, M. C. P., Espírito Santo, A. C. G., \& Motta, S. K. A. (2008). Gênero, vulnerabilidade das mulheres ao HIV/Aids e ações de prevenção em bairro da periferia de Teresina, Piauí, Brasil. Saúde e Sociedade, 17(2), 58-68.

Tesser, C. D. (2006). Medicalização social (I): O excessivo sucesso do epistemicídio moderno na saúde. Interface - Comunicação, Saúde, Educação, 10(19), 61-76.

Viana, F. J. M., Faúndes, A., Mello, M. B., \& Sousa, M. H. (2007). Factors associated with safe sex among public school students in Minas Gerais, Brazil. Cadernos de Saúde Pública, 23(1), 43-51.

Recebido: $30 / 08 / 2012$

$1^{a}$ revisão: 07/09/2012

Aceite final: 13/09/2012 